\title{
LAS PRIMERAS REACCIONES DE LAS COMPAÑÍAS FERROVIARIAS ESPAÑOLAS AL INICIO DE LA COMPETENCIA AUTOMOVILÍSTICA ANTES DE LA GUERRA CIVIL *
}

\author{
JOSÉ LUIS HERNÁNDEZ MARCO \\ Universidad del País Vasco
}

\begin{abstract}
RESUMEN
El trabajo introduce un nuevo elemento explicativo del «problema ferroviario» distinto a la crisis económica o a la acción del Estado y surgido desde finales de la década de los veinte: la competencia del automóvil. Así, se analiza cómo antes de la Guerra Civil el transporte motorizado por carretera había comenzado a competir con el ferroviario, al menos en los tráficos más rentables. Posteriormente se analizan las diversas medidas propuestas por las compañías para intentar contrarrestar esta creciente competencia y los escasos logros prácticos conseguidos.
\end{abstract}

\section{ABSTRACT}

This paper explains the so-called «Spanish railways problem» as a consequence of the new competition that this traditional mean of transport suffered from the rapid development of the automobile industry. Road trans-

N. de E.: Fecha de recepción del artículo en la Revista de Historia Económica: enero, 2001.

Fecha de aprobación del artículo por el Consejo de Redacción: mayo, 2002.

* Este trabajo es uno de los resultados de un proyecto de investigación financiado por la Universidad del País Vasco/EHU (Ref. UPV 012-130-HA 023795) y la DGS del Ministerio de Educación y Cultura (Ref. PS95-0097). Versiones anteriores de este trabajo se discutieron en el Departamento de Historia Económica de la Universidad del País Vasco y en una preconferencia en Montecatini (1998) del Congreso Internacional de la Asociación de Historia Económica (Madrid, 2000). Agradezco las sugerencias de los participantes en aquellas sesiones, así como las de los dos evaluadores anónimos de la RHE. Al intentar incorporarlas creo haber mejorado el resultado final. 
portation more than any other factor was the cause of the financial difficulties of the raliways companies before the Civil War. We also study the reaction of these firms and the failures of all measures that were taken.

JEL Classification: N74, L92, L43.

En la amplia historiografía sobre los ferrocarriles españoles, uno de los temas más recurrentes es el llamado «problema ferroviario». La expresión se fijó tras la publicación en 1918 de los Elementos para el estudio del problema ferroviario en España, obra del Ministro de Fomento Francisco A. Cambó y Batllé. Para la explicación del «problema», aunque fuera de manera secundaria, raramente se ha tenido en cuenta el surgimiento de un factor exógeno a las compañías ferroviarias, distinto de las crisis económicas o de la acción del Estado que unánimemente, junto a los factores endógenos, se consideran las causas fundamentales: el inicio de la competencia del automóvil, y con ella, el comienzo de la pérdida del monopolio en el transporte terrestre moderno del que hasta entonces había gozado el ferrocarril. Las compañías ferroviarias españolas, al menos las dos grandes, como sus homónimas extranjeras, empezaron a tomar conciencia muy pronto, desde mediados de la década de 1920, de la tangible amenaza que representaba la creciente competencia del transporte por carretera, e incluso la introdujeron explícitamente como una de las causas principales de sus problemas financieros en los años treinta.

Este trabajo intenta analizar si la pretendida alarma de la compañías era razonable. Para ello, en las páginas que siguen pretendo contestar a dos preguntas. concretas: ¿desde cuándo y en qué medida amenaza el automóvil al ferrocarril en España?, y en segundo lugar, ¿cómo respondieron y con qué efectividad las compañías ferroviarias españolas a esta amenaza? Así pues, primero argumentaré cómo antes de la Guerra Civil, con la difusión del automóvil, el transporte mecánico por carretera en España había empezado ya a competir seriamente con el ferroviario, como mínimo en algunos de sus tráficos más rentables, en una proporción equivalente a la que llevaría a efecto a principios de los años cincuenta y, en consecuencia, podría estar justificada la temprana alarma de las compañías. Posteriormente me referiré a las diversas medidas que se propusieron para que los ferrocarriles hicieran frente a esa inicial competencia y el grado en que se llevaron a la práctica. 


\section{LA COMPETENCIA DEL AUTOMÓVIL AL FERROCARRIL EN ESPAÑA ANTES DE 1936}

Con la obra más reciente sobre historia general de los ferrocarriles en España ${ }^{1}$, que aborda este tema en la línea de explicaciones anteriores ${ }^{2}$, podemos resumir el «problema ferroviario» de la siguiente forma: la neutralidad española en la Primera Guerra Mundial produjo, entre otras cosas, una intensificación del tráfico de mercancías por ferrocarril. Aunque las compañías habían comenzado con el cambio de siglo a sustituir los carriles de menor peso por otros de mayor resistencia e iniciaron una renovación parcial de sus parques móviles, los resultados de la gestión en los años del conflicto bélico pusieron de manifiesto que estas inversiones fueron totalmente insuficientes, especialmente por el encarecimiento del combustible y de la mano de obra entre otros incrementos de costes, tal como ya señalara Pedro Tedde para las dos grandes compañías de Norte y $\mathrm{MZA}^{3}$. El establecimiento con efecto de 1 de octubre de 1919 de la jornada de ocho horas en los empleados ferroviarios y una, al parecer, escasa revisión de las tarifas, junto a las necesidades de renovación del material, fueron configurando un escenario de creciente intervencionismo estatal por medio de los anticipos reintegrables. Este proceso daría un paso de gigante con el Estatuto Ferroviario de 1924. Para Miguel Artola, los resultados logrados con la aportación estatal se reflejaron de modo inmediato con la eliminación de los obstáculos que desde 1914 habían impedido el aumento del tráfico, tendencia que se mantuvo hasta el advenimiento de la II República, momento en que se plantea una nueva crisis, pero ahora debido a causas de distinta naturaleza ${ }^{4}$.

Efectivamente, desde que en 1929 se suspendieron las aportaciones estatales, las empresas volvieron a experimentar apuros financieros. La nueva crisis ferroviaria fue fundamentalmente propiciada por un descenso de los ingresos derivado de una disminución de los tráficos, más que por un incremento de los gastos, debido ahora al impacto de la crisis económica internacional de 1929 y, como pretendo demostrar, las primeras manifes-

${ }^{1}$ Comín, Martín Aceña, Muñoz y Vidal (1998), vol. I, pp. 281-282 y 343-366.

2 Artola (1978), Tedde (1978), Anes (1978) y Gómez Mendoza (1989a). Por ejemplo, el profesor Artola titula el capítulo 4 con «El problema ferroviario». Son significativos de su hilo explicativo los subtítulos del mismo: «La Guerra Mundial y la crisis del sistema ferroviario», «El "Estatuto Ferroviario" de 1924» y «Crisis y nacionalización».

${ }^{3}$ Los costes de explotación de Norte crecieron entre 1914 y 1919 un 96,1 por 100, y los de MZA un 113,2 por 100. Tedde (1978), pp. 197 y 209.

${ }^{4}$ Artola (1978), p. 430. 


\section{GRÁFICO 1}

Ingresos y gastos de Norte y MZA

(millones de pesetas corrientes)

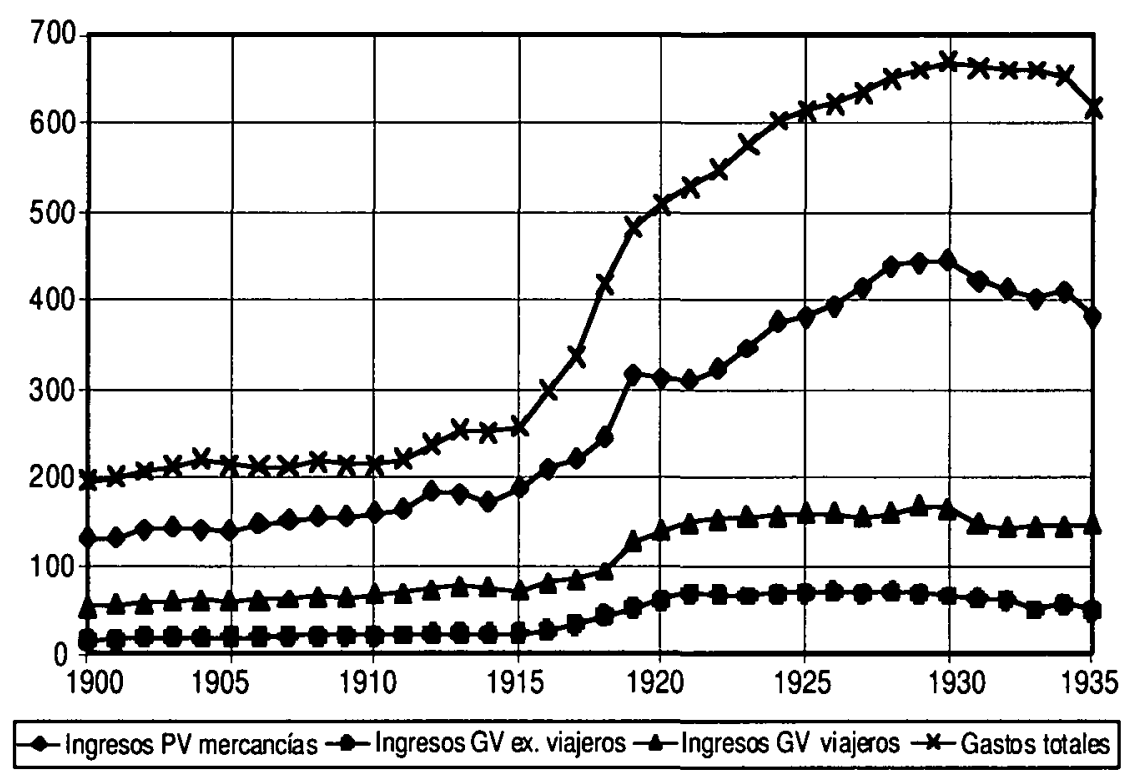

FuENTES: Anes (1978, pp. 487-491) y Tedde (1978, pp. 291-300 y 343-346).

taciones de la competencia automovilística. En el gráfico 1, la pendiente de la curva que refleja los gastos conjuntos totales de las dos principales compañías ferroviarias españolas entre 1915 y 1930 muestra claramente una de las causas de sus problemas financieros, aunque desde la última fecha, como señalaba Tedde ${ }^{5}$, los gastos ceden y luego se contienen.

Pero a este trabajo le interesa más destacar la evolución de los ingresos y para ello he reflejado en el mismo gráfico el desglose de los producidos por el tráfico. Entre 1900 y 1935, las dos grandes recaudaron por tráfico casi 15.118 millones de pesetas corrientes, de los que el 64,3 por 100 correspondieron a la llamada Pequeña Velocidad, es decir, a los producidos

${ }^{5}$ Aunque para Tedde (1978), p. 230, los gastos totales de Norte bajaron un 7,5 por 100 entre 1931 y 1935, es preciso indicar que Gómez Mendoza (1989a), p. 50, sigue considerando también en esta ocasión que la crisis fue «propiciada una vez más por un aumento de los costes de explotación». 
con el transporte ordinario de mercancías, el 25,7 por 100 correspondieron al transporte de viajeros y el 10 por 100 restante a la paquetería y mercancías transportadas en los trenes de viajeros. Teniendo este desigual peso en cuenta, los ingresos de la Pequeña Velocidad crecen casi uniformemente hasta 1919, prácticamente al mismo ritmo que los gastos, se estancan entre 1920 y 1921, y luego reanudan su crecimiento hasta 1930 pero de forma mucho más suave, lo que hace que las curvas tiendan a separarse.

Pero es en las otras dos curvas, correspondientes a la Gran Velocidad, que en conjunto representan algo más de la tercera parte de los ingresos por tráfico, donde podemos ver, a mi juicio, una primera manifestación de la competencia de la carretera. Los ingresos de viajeros y de las mercancías que se transportaban en los trenes donde aquéllos viajaban (la llamada Gran Velocidad) tienen una evolución similar a los de la pequeña velocidad hasta 1921, para desde esa fecha estancarse prácticamente hasta 1930, con una ligera inflexión en los años de la II República. Para las compañías, lo dañino del estancamiento de estos capítulos de ingresos, a pesar de la elevación de tarifas de 1918, es que se trata, como amargamente señala Norte, del «tráfico saneado, el de los buenos rendimientos» ${ }^{6}$. Las mercancías transportadas en la Gran Velocidad corresponden al «grupo de comestibles, frutas, pescados, encargos, es decir, las mercancías de valor», mientras que las transportadas en la Pequeña Velocidad son «los productos en masa, de poco valor, y cuya tarifa apenas cubre los gastos de explotación» ${ }^{7}$. Lo que sucede en las mercancías es trasladable también a los ingresos de viajeros, con peores comportamientos para las tarifas más caras $\left(1 .^{a}\right.$ y $\left.2 .^{a}\right)$ que para la mas barata $\left(3 .^{a}\right)$.

Todo ello queda claramente reflejado en la tabla 1, circunscrita ahora a la Compañía del Norte de España y referenciado a 1920 cuando ya está plenamente consolidada la elevación de tarifas de 1918. En ella puede verse cómo las mercancías a Gran Velocidad difieren de la evolución de las de Pequeña Velocidad a partir de 1924. Si para éstas su máximo de 1930 significa un incremento sobre 1920 del 52 por 100, para aquéllas el máximo de 1926 supone sólo un incremento del 11 por 100. El fenómeno es aún más llamativo en los ingresos producidos por viajeros. A un crecimiento muy moderado de los ingresos totales, con un máximo del 14 por 100 sobre 1920 en 1930 , se corresponde un máximo en la $1 .^{a}$ clase en 1926 pero con un rapidísimo descenso; el máximo de 1921 en la 2. ${ }^{a}$ clase,

\footnotetext{
${ }^{6}$ Norte (1940), p. 11
}

7 Ibidem, p. 364. 
TABLA 1

Ingresos por tráfico de la Compañia del Norte en pesetas corrientes $(1920=100)$

\begin{tabular}{|c|c|c|c|c|c|c|}
\hline \multirow{2}{*}{$A \tilde{n} o$} & \multicolumn{6}{|c|}{ Ingresos } \\
\hline & Viajeros & $1 .^{a}$ clase & $2 .{ }^{a}$ clase & $3 .^{a}$ clase & Merc. GV & Merc. $P V$ \\
\hline $1920 \ldots \ldots$ & 100,0 & 100,0 & 100,0 & 100,0 & 100,0 & 100,0 \\
\hline $1921 \ldots \ldots \ldots \ldots$ & 106,5 & 104,1 & 112,5 & 105,4 & 115,8 & 100,4 \\
\hline $1922 \ldots \ldots \ldots \ldots$ & 105,7 & 106,8 & 111,1 & 103,7 & 109,2 & 106,7 \\
\hline $1923 \ldots \ldots \ldots \ldots$ & 106,5 & 114,2 & 107,4 & 103,3 & 102,8 & 113,9 \\
\hline $1924 \ldots \ldots \ldots \ldots$ & 109,6 & 119,6 & 107,9 & 106,2 & 108,0 & 123,1 \\
\hline $1925 \ldots \ldots \ldots \ldots$ & 109,4 & 123,5 & 102,5 & 105,7 & 109,7 & 125,4 \\
\hline $1926 \ldots \ldots \ldots \ldots$ & 110,9 & 130,5 & 93,1 & 108,3 & 111,2 & 129,1 \\
\hline $1927 \ldots \ldots \ldots \ldots$ & 107,5 & 129,1 & 86,9 & 104,9 & 109,3 & 136,3 \\
\hline $1928 \ldots \ldots \ldots \ldots$ & 107,4 & 125,2 & 83,5 & 106,9 & 111,1 & 145,4 \\
\hline $1929 \ldots \ldots \ldots \ldots$ & 111,4 & 127,8 & 77,3 & 113,9 & 105,8 & 148,5 \\
\hline $1930 \ldots \ldots \ldots \ldots$ & 114,3 & 123,6 & 76,6 & 120,5 & 103,3 & 152,0 \\
\hline $1931 \ldots \ldots \ldots \ldots$ & 103,1 & 100,6 & 70,5 & 112,3 & 100,8 & 146,7 \\
\hline $1932 \ldots \ldots \ldots \ldots$ & 98,6 & 89,2 & 64,6 & 111,0 & 105,8 & 143,3 \\
\hline $1933 \ldots \ldots \ldots \ldots$ & 100,3 & 79,0 & 78,9 & 112,8 & 91,8 & 137,0 \\
\hline $1934 \ldots \ldots \ldots \ldots$ & 100,9 & 82,9 & 77,0 & 117,4 & 97,7 & 142,5 \\
\hline $1935 \ldots \ldots \ldots \ldots$ & 100,7 & 79,3 & 81,4 & 117,0 & 82,4 & 134,2 \\
\hline
\end{tabular}

FUENTE: Norte (1940), cuadros 1-8.

la que peor se comporta, con un mejor resultado que no llega a un incremento del 13 por 100 sobre 1920 ; y el máximo de la $3 .^{a}$ clase en 1930 , coincidente en la fecha con las mercancías de pequeña velocidad, pero dos veces menor.

El mismo fenómeno, ahora desde otro punto de vista, puede verse en la tabla 2, ahora en pesetas constantes de 1913 y en relación al GNB español. Los ingresos ferroviarios crecen más que el PIB en ambos períodos. Pero, mientras entre 1900 y 1913 las tasas de crecimiento de los ingresos son tres veces superiores a las del GNB, entre 1919 y 1930 esto sólo sucede con los ingresos provenientes de la Pequeña Velocidad. Al mismo tiempo, mientras las tasas de crecimiento de la Pequeña Velocidad y el GNB se multiplican por 2,6 en 1919-1930 en relación con el primer período, en la Alta Velocidad sólo se multiplican por 1,6 ó 1,3. Como se verá, hasta 1913, la presencia de automóviles en España, como en otros países europeos, es casi testimonial, mientras que durante los años veinte crecerá a fuerte ritmo la motorización española. 
TABLA 2

Tasas de crecimiento medio anual de los ingresos de Norte y $M Z A$ (pesetas de 1913)

\begin{tabular}{|c|c|c|c|}
\hline & $1900 / 1913(a)$ & $1919-1930(b)$ & $(b) /(a)$ \\
\hline Mercancías Pequeña Velocidad (1) ....... & $2,32 \%$ & $6,14 \%$ & 2,6 \\
\hline Mercancías Gran Velocidad (2) .............. & $2,54 \%$ & $3,37 \%$ & 1,3 \\
\hline 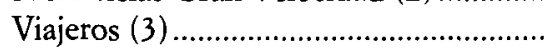 & $2,39 \%$ & $3,80 \%$ & 1,6 \\
\hline 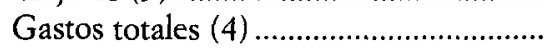 & $1,15 \%$ & $5,02 \%$ & 4,4 \\
\hline GNB (5) & $0,77 \%$ & $1,97 \%$ & 2,6 \\
\hline$(1) /(5)$ & 3,0 & 3,1 & \\
\hline$(2) /(5)$ & 3,3 & 1,7 & \\
\hline 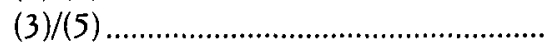 & 3,1 & 1,9 & \\
\hline$(4) /(5)$ & 1,5 & 2,5 & \\
\hline
\end{tabular}

FUENTES: Las del gráfico 1, y para el GNB, A. Carreras (1990, pp. 185-187).

Para las dos grandes compañías ferroviarias españolas, los culpables de esta situación eran claros: el camión y el autobús. Así, MZA indica que

«minuciosos estudios realizados por la Compañía de MZA demuestran que el tráfico de viajeros y trenes especiales se halla sometido, desde el año 1920, a la competencia de los transportes por carretera [...] Sobre el tráfico de gran velocidad de mercancías se observa la influencia del camión, principalmente a partir de 1926 [...] el descenso del tráfico con relación a períodos en que el incremento normal se habría debilitado, supone en resumen para 1930:

\begin{tabular}{lc} 
& Millones de pesetas \\
\cline { 2 - 2 } Viajeros y gran velocidad & 14,2 \\
Pequeña velocidad & 23,4 \\
Total & 37,6
\end{tabular}

Tales descensos se provocan por la crisis económica del país y por la competencia de los transportes por carretera: esta Compañía considera que la competencia por carretera supone, para los viajeros y gran velocidad, un 75 por 100 de la reducción, y para los transportes de pequeña velocidad, un 25 por 100 de aquella reducción» 8 .

Ello supone que MZA, ponderando lo que como media suponen los distintos tipos de ingresos, imputa a la competencia de la carretera un 43,6 por 100 del descenso de sus ingresos totales en 1930.

\footnotetext{
${ }^{8}$ Compañía MZA (1931), pp. 45-49.
} 
La Compañía del Norte de España, por su parte, interpreta los resultados de los estudios de MZA de forma mucho más alarmante, puesto que llega a afirmar que

«se reparten [...] las causas de la reducción, atribuyendo a la crisis un 25 por 100 de participación y el 75 por 100 a la competencia de la carretera. No puede dudarse que en el automóvil, en el autobús, está la verdadera causa de la situación, y que él es el verdadero competidor del ferrocarril, tanto para viajeros como para mercancías» 9 .

Aunque pudiera pensarse que estos contundentes testimonios son de parte $y$, por tanto, exagerados e interesados al dar más importancia a problemas de fuera que a los internos, la mayoría de historiadores españoles que se han ocupado del tema, quizá con la excepción de Albert Carreras, han señalado que la competencia de la carretera incidirá significativamente sólo bastantes años después ${ }^{10}$. Incluso a pesar de algunas referencias directas o indirectas a esa competencia, en la reciente síntesis colectiva sobre la historia ferroviaria española son otras las explicaciones que allí se dan sobre las causas del estancamiento (1926-1930) y posterior caída (tras 1930) del tráfico de viajeros en las grandes compañías, que «no siguió fielmente los ciclos de la economía española entre 1919 y 1930», y no se menciona tampoco la posible competencia del automóvil ${ }^{11}$. A mi juicio, ello pudiera ser debido a lo que se ha denominado «la negligencia de los historiadores hacia el transporte por carretera» derivada de la relativa escasez de evidencias históricas en comparación con los canales y los ferrocarriles ${ }^{12}$. Así, en el caso español, mientras disponemos de la serie casi completa del output ferroviario de vía ancha desde 1868 para las mercancías y desde 1913

9 Norte (1940), p. 359.

${ }^{10}$ Carreras (1988) tituló uno de sus apartados precisamente «La carretera contra el carril». Un ejemplo de ese tratamiento breve y «retrasador», en Tortella (1994), p. 114: «[...] la rapidez con que creció el tráfico ferroviario a partir de 1870 indica que había una fuerte demanda de transporte interior, en el que el tren sólo competía con la carretera, a la cual sería muy superior hasta mediado el siglo xx (cuando la gran difusión del motor de gasolina populariza tremendamente el tráfico por carretera)». También Muñoz (1995), pp. 81-82.

11 Comín, Martín Aceña, Muñoz y Vidal (1998), por ejemplo, la referencia a la temprana competencia de la carretera (desde 1915) en la línea del Ferrocarril de Amorebieta a Guernica (vol. 1, p. 252). Y sin embargo, páginas después, para justificar la evolución mencionada del tráfico de viajeros en Norte, MZA o Andaluces se achaca incluso al hecho de que «la demanda de transporte ya estaba saturada» (vol. 1, p. 344).

12 Barker y Gerhold (1993), p. 11. 
para los pasajeros ${ }^{13}$, y desde 1950 también el de la vía estrecha ${ }^{14}$, es precisamente sólo desde este último año cuando arranca la serie oficial del output del transporte por carretera ${ }^{15}$, aunque existen algunas estimaciones, referidas exclusivamente a pasajeros transportados según el modo, desde $1940^{16}$. Esta limitación de las fuentes estadísticas disponibles ha contribuido a fijar la imagen del predominio del modo de transporte ferroviario sobre la carretera hasta 1954 en las mercancías y hasta 1956 en los viajeros ${ }^{17}$. Así pues, para dilucidar si la percepción de las compañías ferroviarias sobre la competencia del automóvil a principios de los años treinta era o no exagerada, deberemos procurarnos de otros elementos de análisis al no cubrir las estadísticas oficiales esos años.

Antes que nada creo que es importante señalar que si en 1950 el output de la carretera supone ya un 66 por 100 del ferroviario en los viajeros y un 68 por 100 en las mercancías ${ }^{18}$, ello se consigue con un parque automovilístico de un tamaño casi idéntico, aunque notablemente enve-

${ }^{13}$ Gómez Mendoza (1989b), pp. 288-291.

${ }^{14}$ De acuerdo con las Estadísticas de Transportes. Series cronológicas (1950-1980), del Instituto de Estudios de Transportes y Comunicaciones (IETC).

${ }^{15}$ Los datos de la fuente mencionada en la nota anterior son los utilizados, por ejemplo, por Izquierdo (1980), pp. 416 y 430, y reiterados en Carreras (1988), p. 165.

16 CECA (1975), tabla 4.4, y citada por Muñoz (1995), pp. 173-174. El primer dato utilizable, con cautelas, es el de 51,028 millones de pasajeros transportados por carretera en 1940.

17 Éstas son las primeras fechas en que, según las estimaciones oficiales, el tráfico por carretera en la red estatal superaría al ferroviario (RENFE y vía estrecha):

Output ferroviario y del transporte por carretera (millones)

\begin{tabular}{|c|c|c|c|c|c|c|}
\hline \multirow[b]{2}{*}{$A \bar{n} o$} & \multicolumn{2}{|c|}{ Carretera } & \multirow[b]{2}{*}{$\begin{array}{c}\text { Total: } \\
\text { viajeros/km }\end{array}$} & \multirow[b]{2}{*}{$\begin{array}{l}\text { Total: } \\
T \mathrm{~m} / \mathrm{km}\end{array}$} & \multicolumn{2}{|c|}{ Ferrocarril } \\
\hline & Viajeros/km & $T \mathrm{~m} / \mathrm{km}$ & & & $\begin{array}{l}\text { Via ancha: } \\
\text { viajeros/km }\end{array}$ & $\begin{array}{c}\text { Via ancha: } \\
T \mathrm{~m} / \mathrm{km}\end{array}$ \\
\hline $1950 \ldots \ldots . .$. & 5.403 & 5.443 & 8.228 & 8.036 & 7.093 & 7.305 \\
\hline $1951 \ldots \ldots \ldots$ & 5.607 & 5.681 & 8.450 & 8.677 & 7.284 & 7.890 \\
\hline $1952 \ldots \ldots \ldots$ & 5.926 & 6.884 & 9.108 & 9.390 & 7.851 & 8.536 \\
\hline $1953 \ldots \ldots . .$. & 6.379 & 8.827 & 9.255 & 9.495 & 7.978 & 8.631 \\
\hline $1954 \ldots \ldots . . .$. & 7.311 & 9.237 & 9.140 & 8.988 & 7.879 & 8.306 \\
\hline $1955 \ldots \ldots . . .$. & 8.140 & 10.203 & 9.303 & 9.019 & 8.020 & 8.199 \\
\hline $1956 \ldots \ldots \ldots$ & 9.552 & 13.173 & 9.920 & 9.433 & 8.552 & 8.599 \\
\hline $1957 \ldots \ldots . . .$. & 11.197 & 14.524 & 9.999 & 10.125 & 8.608 & 9.225 \\
\hline
\end{tabular}

FueNTE: Izquierdo (1980), pp. 430 y 432, y Gómez Mendoza (1989), p. 289.

18 Si tenemos en cuenta tan sólo el output ferroviario de vía ancha, expresado en las dos últimas columnas de la tabla de la nota 17 , las cifras subirian a un 76 por 100 en los viajeros y a un 75 por 100 en las mercancías. 
jecido, al existente en España a la altura de 1930, tras un intenso proceso de matriculación de automóviles desde finales de la Gran Guerra. Efectivamente, si entre 1906 y 1917 se habían matriculado en España poco más de 15.000 vehículos de motor, entre 1918 y 1930 se registraron 249.948 nuevas matriculaciones. Con ello España pasaba de una ratio de algo menos de dos vehículos en uso por cada 1.000 habitantes en 1922 a otra de ocho en los primeros años treinta, en la línea y al nivel italiano y alemán. En vehículos de cuatro y más ruedas, el máximo de la matriculación anual de 1929, 34.326 automóviles, no se superaría hasta 1956 y de manera continuada, sólo con los 43.618 turismos y vehículos industriales del año $19588^{19}$. El retraso en la motorización española provocado por la Guerra Civil y el primer franquismo queda suficientemente expresado en la tabla 3.

Las divergencias entre ambas fechas en turismos y vehículos comerciales (camiones, furgonetas y camionetas), dado que la fuente es la misma, la Patente Nacional de Circulación, se puede explicar, a mi juicio, como consecuencia de las enormes dificultades en el aprovisionamiento de combustible y recambios para usos privados en los años cuarenta y el proceso de reconversión de antiguos vehículos de turismo en pequeños vehículos comerciales en las autárquicas circunstancias de la posguerra ${ }^{20}$. Pero si bien conocemos las características fundamentales del parque español de vehículos en 1950 porque fueron publicadas por el Instituto Nacional de Estadística en 1952, aún no es posible conocerlas, con el mismo detalle, para $1930^{21}$. Ello hace que tengamos problemas para poder estimar la capacidad de transporte del parque español de automóviles anterior a la Guerra Civil. De todas formas vamos a intentar una aproximación indirecta que posiblemente pueda aceptarse como una estimación plausible.

Aunque algunas de las características del parque español no habrían variado esencialmente entre los años 1930 y $1950^{22}$, parece evidente, como ya he señalado, que el transporte privado de pasajeros (turismos) cedió al transporte de mercancías parte de su infraestructura móvil mediante

${ }^{19}$ Para la caracterización del parque español en relación a otros países y su proceso de formación, incluido el traumático efecto de la Guerra Civil y el primer franquismo, Hernández Marco (1996). Las comparaciones con Alemania y Francia son de Barker (1987), pp. 2-4.

${ }^{20}$ Carreras (1988), pp. 157 ss.; Catalán (1995), pp. 252-254, y Hernández Marco (1996).

${ }^{21}$ Se está llevando a cabo una investigación en este sentido, aún no concluida, basada en la explotación de una amplia muestra de datos municipales de la Patente Nacional de Circulación.

${ }^{22}$ En Hernández Marco (1996) he argumentado que dada la relativa debilidad de la matriculación de vehículos nuevos en la década de 1940, los existentes en 1950 deberían reflejar en gran medida las características del parque anterior a la Guerra Civil. Un ejemplo 


\section{TABLA 3}

Parque español de automóviles autorizados a circular

\begin{tabular}{lrr}
\hline Clase & \multicolumn{1}{c}{1930} & \multicolumn{1}{c}{1950} \\
\hline Turismos ...................................... & 105.296 & 67.158 \\
Taxis y autobuses....................... & 27.469 & 29.643 \\
Camiones y camionetas ................ & 47.208 & 76.744 \\
Motocicletas .............................. & 14.780 & 16.611 \\
\cline { 2 - 3 } & 194.753 & 190.156 \\
\hline
\end{tabular}

Fuentes: Patente Nacional de Circulación. Para 1930, AEE (1933), multiplicando sus valores por 1,090839 para incluir al País Vasco y Navarra, de acuerdo con su matriculación acumulada a 1930. Para 1950, INE (1952).

reconversión en furgonetas y camionetas, tal como nos ha mostrado la tabla 3. Pero también algunas pistas nos indican que debía ser bastante parecido en ambas fechas el parque destinado al transporte público de pasajeros y el de mercancías mediante medianos y grandes camiones. Así, los «nuevos» camiones en circulación en la década de los cuarenta estarían formados como máximo por los 17.044 vehículos industriales importados desde 1940 a $1950^{23}$ y las escasas unidades fabricadas en España en las condiciones económicas nacionales e internacionales de esos años ${ }^{24}$, por lo que la mayor parte del parque en este segmento debía estar ya circulando antes de 1940. Si a esto se añade que, en los países europeos más motorizados, las características en posibilidad de carga de los vehículos no varió mucho entre los años 1930 y $1950^{25}$, se podría aplicar, sin riesgo de grandes errores, la distribución de la carga máxima en 1950 a los datos de 1930.

de la permanencia de las características del parque para el caso de la ciudad de Madrid, entre 1931 y 1948, en López Gómez (1983), p. 59.

${ }^{23}$ Número que es preciso contrastar con los 62.698 camiones importados entre 1925-1935, según la misma fuente [INE (1952), p. 92]. Es decir, en el mismo número de años, antes de la Guerra Civil se importaron en España un número de camiones 3,7 veces superior a los años cuarenta.

${ }^{24}$ Las reducidas capacidades de la fabricación nacional en esos años incluso para las fábricas extranjeras instaladas en España antes de la Guerra Civil pueden verse, por ejemplo, en Catalán (1995), pp. 149 y 153-155; San Román (1995), pp. 46-49 y 113-120, o Martín Aceña y Comín (1991), pp. 225-229.

25 Por ejemplo, en el Reino Unido en 1938 el 44 por 100 de los vehículos comerciales pesaban en vacío menos de $1,5 \mathrm{Tm}$; otro 44 por 100 entre 1,5 y $2,5 \mathrm{Tm}$; un 8 por 100 entre 2,5 y $4 \mathrm{Tm}$, y sólo un 4 por 100 más de $4 \mathrm{Tm}$. En 1950 , esas mismas proporciones eran: 43 por 100 menos $1,5 \mathrm{Tm} ; 47$ por 100 entre 1,5 y $3 \mathrm{Tm} ; 8$ por 100 entre 3,5 y 
Según el INE, estaban autorizados a transportar más de 3 toneladas algo más de 43.000 vehículos del parque existente en 1950. Si descontamos los autobuses con patente de circulación, quedarían, por tanto, 36.870, el 48 por 100 de los camiones y camionetas reseñados en la tabla 3 , pudiendo el resto transportar hasta un máximo de $3 \mathrm{Tm}$. Si aplicamos a 1930 los mismos cálculos, justificados por lo que he indicado sobre las similitudes en las características de los vehículos industriales, los camiones autorizados a transportar más de 3.000 kilos serían 38.754. De esta forma se puede estimar que la capacidad de carga de los camiones y camionetas sería en 1950 de unas $245.000 \mathrm{Tm}$, un 28 por 100 más que las $191.000 \mathrm{Tm}$ que sería capaz de cargar el parque de 1930, derivado fundamentalmente, si los cáculos son correctos, de la mayor utilización en 1950 de turismos originarios, transformados en camionetas para transporte de mercancías, más que por un aumento significativo de vehículos de gran capacidad de carga. En consecuencia, creo que no es muy aventurado estimar que si se acepta que la capacidad de carga del parque español de 1950 fue capaz de transportar casi cinco millones y medio de $\mathrm{Tm} / \mathrm{km}$ según la tabla de la nota 17, en 1930 el transporte por carretera podría haber sido capaz de transportar 4.265 millones de $T \mathrm{~m} / \mathrm{km}$, es decir, el 78 por 100 de las que ese año transportaron los ferrocarriles de vía ancha ${ }^{26}$.

Pero aun suponiendo correctos estos cáculos sobre el parque automovilístico dedicado al transporte de mercancías, por las características técnicas de los vehículos y de la red de carreteras, la inmensa mayoría de esta capacidad de carga debía emplearse para repartir mercancías en los ámbitos urbanos y quizá como máximo a transportar algunas mercancías a puntos relativamente próximos, por lo que la competencia al ferrocarril sería aún muy limitada. Ello debió ser así porque incluso en sociedades

5, y sólo un 2 por 100 de más de $5 \mathrm{Tm}$. La carga máxima en GB en estos momentos era aproximadamente el doble del peso en vacío; Barker y Gerhold (1993), pp. 86 y 92.

${ }^{26}$ El cálculo está basado en la tabla 3 y en la distribución del total del parque por carga máxima autorizada en 1950 [INE (1952), pp. 30-31]. Según el organismo oficial, de los poco más de 190.000 vehículos del parque español total, tenían autorización para transportar menos de 1.000 kilos el 52 por 100 , es decir, casi todos los turismos, taxis y motocicletas existentes; el 25 por 100 entre una y tres toneladas, y el 23 por 100 restante más de 3.000 kilos. Esta última cantidad bruta es la utilizada como base en el parque de camiones, pues por lógica, salvo los autobuses, sólo los camiones estarían autorizados a transportar esa cantidad de carga. Para simplificar los cálculos, se ha procedido aplicando a los vehículos de menos de $3 \mathrm{Tm}$ de carga máxima (los restantes tras descontar del parque la cantidad bruta anterior) la media de $2 \mathrm{Tm}$, y a los de más de $3 \mathrm{Tm}, 4,5 \mathrm{Tm}$ como promedios de carga autorizada. El output ferroviario de 1930, 5.450,3 millones, en Gómez Mendoza (1989b), p. 289. 
europeas más motorizadas, como la británica, sólo desde mediados de los años cincuenta es datable el desarrollo de la circulación de grandes camiones de cuatro ejes, dedicados al transporte de ámbito nacional e internacional utilizando las rápidas autovías y autopistas. Pero también en el Reino Unido ya antes de la Segunda Guerra Mundial el transporte comercial motorizado había reemplazado «completamente» al transporte en carros y sustraído al ferrocarril la mayor parte del tráfico en trayectos inferiores a los 100 kilómetros ${ }^{27}$.

En el caso español, además de haber comenzado la competencia al propio ferrocarril, como se quejaban las Compañías, aunque sólo fuera en esos trayectos cortos y para algunas mercancías, algunos datos parciales permiten pensar también que el reemplazo del carro tradicional de tracción animal ya había avanzado bastante, al menos en el mundo urbano, antes de la guerra del 36. Algunas de las cosas que sabemos sobre el transporte ferroviario de mercancías por la Compañía del Norte de España puede ofrecer algún indicio en este sentido. La cabaña ganadera productora de carne y leche crece significativamente en el primer tercio del siglo $\mathrm{xx}$ y con ella creció el tráfico de alimentos a ella destinada, es decir, los cereales pienso, incluso más que el de harina ${ }^{28}$ como muestra el gráfico 2 . Frente a ello, el mismo gráfico indica que el tráfico de «heno, paja y forrajes», fundamentalmente destinado para alimento y cama del ganado caballar y mular de zonas deficitarias de cereales, tiene en los años veinte un comportamiento totalmente plano respecto al tráfico de 1913, cuando de haber seguido pautas de consumo similares debería comportarse de una manera más paralela al tráfico de cereales de donde como subproducto procedían.

Una posible causa de este diferente comportamiento podría ser el estancamiento o disminución del consumo de paja en los núcleos urbanos, en un contexto de crecimiento de la urbanización española y consiguientemente de las necesidades de transporte urbano. Ello sería indicador de una disminución de los animales de carga y tiro, sólo compensado por el incremento de los vehículos de motor. Así, por ejemplo, en Madrid en 1926, cuando circulaban 9.650 turismos particulares y 1.720 camiones, lo seguían haciendo 1.250 carruajes de lujo y 6.585 carros de tracción animal. Sólo cinco años después se había más que doblado el número de turismos y camiones, 21.931 y 4.211 , respectivamente, y por ello, casi

\footnotetext{
${ }^{27}$ Barker y Gerhold (1993), pp. 92-95.

${ }^{28}$ GEHR (1983), pp. 208 ss. Y posteriormente Jiménez Blanco (1986), pp. 64 ss.
} 


\section{GRÁFICO 2}

Tráfico de mercancias de Norte. $1913=100$

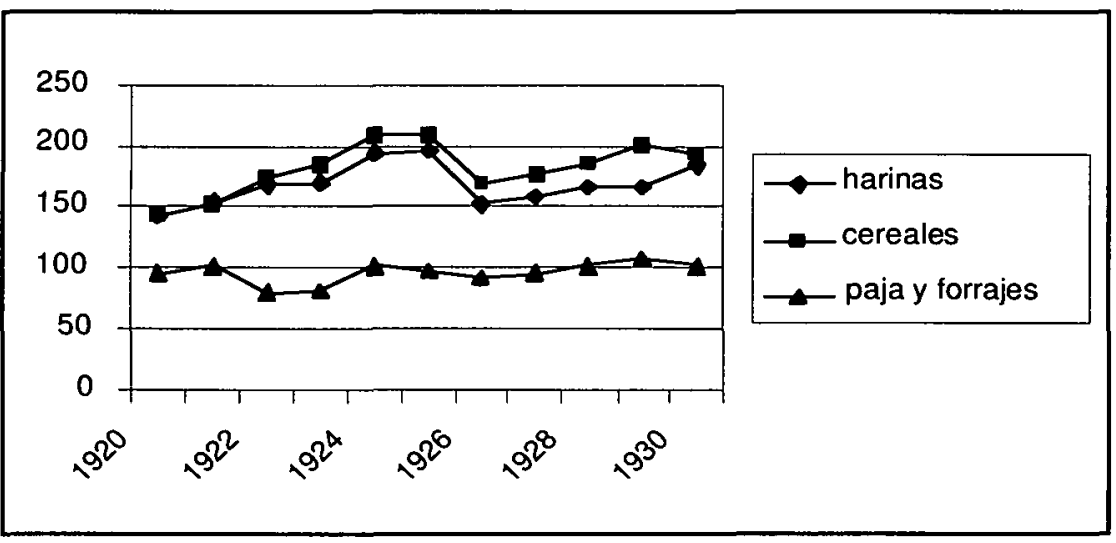

FUENTE: Hernández Marco (1997), Apéndice 1.1.

desaparecido los carruajes, 52, y reducido a casi la mitad, 3.503, los carros existentes ${ }^{29}$.

Como algunos de estos datos ya adelantan, más significativa debió ser la competencia al ferrocarril en el transporte de viajeros. Primero y de manera destacada porque el transporte privado motorizado era muy superior en 1930 que en 1950. Como se vio en la tabla 3, en la primera de las fechas había casi 40.000 turismos más autorizados a circular, lo que supone un 57 por 100 más, y casi los mismos taxis que en la segunda. Además son concocidas las restricciones de combustible para usos particulares en el período autártico. En segundo lugar, también puede verse una cierta competencia al ferrocarril en el transporte público interurbano en autobús. La relativa mayor abundancia de información concerniente al transporte público de viajeros por carretera hace menos necesarias las estimaciones, aunque no las evite totalmente. Si hacemos un cáculo del mismo tipo que el realizado para las mercancías, si con un parque de algo más de 113.000 vehículos de viajeros en 1950 se transportaron 5.403 millones de viajeros $/ \mathrm{km}$, con los más de 147.000 de 1930 se podrían haber transportado 7.029 millones de viajeros $/ \mathrm{km}$, cifra casi idéntica a los transportados por los ferrocarriles de vía ancha en 1950. Pero como las preo-

\footnotetext{
${ }^{29}$ López Gómez (1983), p. 59.
} 
cupaciones de los ferrocarriles, como transportistas públicos, se centrarían especialmente en el transporte público por carretera, puesto que poco podían hacer para evitar la difusión privada del automóvil, es necesario profundizar algo más en el transporte interurbano de viajeros por carretera.

La tabla 4 nos muestra cómo las magnitudes de este transporte público por carretera en los primeros años treinta, sólo empezarian a alcanzarse en 1949-1950 y que si nuestros cálculos son correctos, los 70 millones de viajeros transportados en autobuses interurbanos como promedio entre 1930 y 1933 suponen el 60 por 100 del total de viajeros transportados en 1930 por los ferrocarriles de vía ancha españoles ${ }^{30}$. Aunque no todos estos viajeros lo hubieran hecho por ferrocarril en ausencia de autobuses - por ejemplo, por no estar sus localidades de residencia y/o destino comunicados por ferrocarril-, parece claro que alguna incidencia tendría que tener en el transporte ferroviario de viajeros esta capacidad de transporte público por carretera, sector que había alcanzado tal envergadura que tuvo que ser objeto de regulación.

En España, la regulación con carácter general del transporte público por carretera mediante concesiones ${ }^{31}$ se lleva a efecto a raíz de la publicación del Real Decreto de 4 de julio de 1924 y su Reglamento de desarrollo (Real Orden de 11 de diciembre de 1924), que, con ligeras modificaciones, siguió vigente hasta principio de 1929, en que una nueva batería normativa (Reales Decretos de 22 de febrero y 21 de junio de 1929 y Reglamento de aplicación de ambos de 22 de junio del mismo año) precisa la explotación comercial de los transportes mecánicos, hace una clasificación de servicios, atribuye competencias a diversos organismos administrativos e inspectores y detalla los deberes y derechos de los transportistas y las sanciones que pudieran cometerse en la explotación de los servicios concedidos. Algunas de estas disposiciones fueron parcialmente modificadas durante la II República.

En resumen, podemos indicar que el sistema español de transportes públicos por carretera descansaba en los siguientes principios: 1. Todos los servicios de transportes son establecidos con carácter temporal (máximo veinte años); 2. Se distinguen como tipos de concesión fundamentales los servicios regulares y los discrecionales; 3 . Los regulares, otorgados mediante concurso, se denominan de la clase A, están sujetos a un itinerario y horario fijos, tienen un recorrido mínimo de ida y vuelta diario y están obligados

\footnotetext{
30 117,1 millones según Gómez Mendoza (1989b), p. 289.

31 Seguimos, en lo que sigue, la completa síntesis normativa de Imedio (1934).
} 
TABLA 4

Transporte público por carretera

(lineas autorizadas)

\begin{tabular}{ccccc}
\hline Año & Lineas & $K m$ & Autobuses & $\begin{array}{c}\text { Viajeros } \\
\text { (millones) }\end{array}$ \\
\hline $1930 \ldots \ldots \ldots \ldots .$. & 2.135 & 81.739 & 4.193 & 65,14 \\
$1931 \ldots \ldots \ldots \ldots$. & 2.223 & 85.922 & 4.366 & 67,83 \\
$1932 \ldots \ldots \ldots \ldots$. & 2.346 & 89.344 & 4.608 & 71,58 \\
$1933 \ldots \ldots \ldots \ldots$. & 2.447 & 90.957 & 4.806 & 74,66 \\
$1942 \ldots \ldots \ldots \ldots$. & 1.742 & 79.155 & 3.336 & 48,86 \\
$1943 \ldots \ldots \ldots \ldots$. & 1.836 & 84.661 & 3.507 & 57,22 \\
$1944 \ldots \ldots \ldots \ldots$. & 1.904 & 85.743 & 3.388 & 60,08 \\
$1945 \ldots \ldots \ldots \ldots$. & 1.852 & 82.246 & 3.319 & 45,81 \\
$1946 \ldots \ldots \ldots \ldots .$. & 1.915 & 79.073 & 3.591 & 48,75 \\
$1947 \ldots \ldots \ldots \ldots$. & 2.001 & 84.894 & 3.815 & 62,62 \\
$1948 \ldots \ldots \ldots \ldots$. & 2.062 & 89.077 & 4.134 & 65,12 \\
$1949 \ldots \ldots \ldots \ldots .$. & 2.130 & 90.111 & 5.074 & 76,44 \\
$1950 \ldots \ldots \ldots \ldots$. & 2.451 & 99.611 & 5.175 & 85,44 \\
\hline
\end{tabular}

FUENTES: 1930-1933: AEE (1932, p. 251, y 1934, p. 352); 1942-1950: AEE (1953, p. 340). Las cifras en itálica, autobuses y millones de viajeros entre 1930 y 1933 , se han estimado con el promedio de 1,96 autobuses/ínea y 30.514 viajeros por línea entre 1942 y 1950 .

a transportar la correspondencia pública; 4. Los que no cumplen todas las condiciones anteriores se denominarán discrecionales, divididos en la clase $\mathrm{B}$ (servicios temporales de viajeros, mercancías o mixtos, con duración, itinerario y horarios fijados al ser autorizados) y clases $\mathrm{C}$ (servicios libres de viajeros a vehículo completo) y $\mathrm{D}$ (servicios públicos exclusivamente de mercancías con horario indeterminado) ${ }^{32}$.

Las líneas de transporte que se reflejaban en la tabla 4 son las denominadas de las clases A y B y eran las que preocupaban fuertemente a las compañías ferroviarias, puesto que en algunos trayectos podrían detraer posibles viajeros del ferrocarril hacia la carretera. Esta preocupación llevó,

${ }^{32}$ Estos, según la Real Orden de 18 de noviembre de 1929, eran los más habituales entre los de mercancías. Con esta norma, además, se instaura la costumbre de otorgar a una asociación de transportistas un número determinado de licencias que pueden usarse cuando salgan fuera de los limites urbanos. Es así para la «Federación Industrial de Auto-Transportes de Cataluña», que se le conceden 100 licencias provinciales y 50 interprovinciales, para que puedan ser usadas por sus 1.012 asociados y 1.500 camiones. 
por ejemplo, en 1931 a MZA a realizar un listado de las líneas de transporte de viajeros que podían competir con sus líneas por afectar los recorridos de la carretera a alguna de sus estaciones. De ese listado hemos resumido algunos aspectos en la tabla 5, que permiten ilustrar algunas características del transporte público de viajeros por carretera en la España de los años treinta.

\section{TABLA 5}

Características de las líneas de autobuses operantes en 1931 en el territorio de $M Z A$

\begin{tabular}{|c|c|c|c|}
\hline Caracteristicas & Total & Promedio & Num de casos \\
\hline 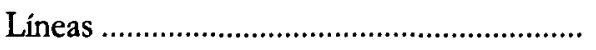 & 379 & & \\
\hline Número de trayectos diarios ............................. & 1.047 & & \\
\hline Paradas en estaciones MZA ............................. & 580 & & \\
\hline 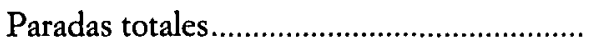 & 2.181 & & \\
\hline Trayectos $(\mathrm{km})$ & 20.784 & 26,5 & 379 \\
\hline Velocidad (km/h.) & & 24,0 & 351 \\
\hline Duración (horas) & & 2,4 & 351 \\
\hline Tarifa $1 .^{a}$ clase $(\mathrm{ptas} / \mathrm{km})$ & & 0,14 & 163 \\
\hline 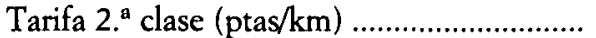 & & 0,12 & 319 \\
\hline 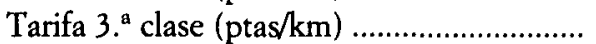 & & 0,11 & 63 \\
\hline
\end{tabular}

FuENTE: MZA, «Líneas de automóviles: 1931» (Fundación de los Ferrocarriles Españoles: $\mathrm{IIIF} / 572$ ).

La posible competencia realizada al ferrocarril por alguna de estas líneas de autobuses parece evidente que se basaba en esas velocidades medias de $24 \mathrm{~km} /$ hora en trayectos de menos de 100 kilómetros ${ }^{33}$, la mayoría con servicios diarios de ida y vuelta o más, con una duración de menos de cuatro horas y con unas tarifas plenamente competitivas con el ferrocarril no tanto en pesetas/kilómetro como en el precio global del viaje ${ }^{34}$. Pero está claro que la competencia sólo podía producirse en aquellos trayectos

${ }^{33}$ La distribución de las 379 líneas según el kilometraje de sus itinerarios es: 7,1 por 100 de menos de $10 \mathrm{~km} ; 22,2$ por 100 de 11 a $25 \mathrm{~km} ; 29,8$ por 100 de 26 a $50 \mathrm{~km}$; 31,4 por 100 de 51 a $100 \mathrm{~km} ; 6,6$ por 100 de 101 a $200 \mathrm{~km}$, y 2,9 por 100 de más de $200 \mathrm{~km}$.

${ }^{34} \mathrm{MZA}$ calcula en 1930 el ingreso por viajero/km en 0,0546 ptas. [MZA (1931), p. 28]. En Norte el ingreso por viajero kilométrico va de 0,0591 en 1928 a 0,0538 en 1935 [Norte (1940), p. 358]. Aunque estos ingresos medios no hay que confundirlos con las tarifas, las menores distancias por carretera en la mayoría de los trayectos reducirian estas diferencias para el precio del viaje, a lo que habría que añadir los ahorros intangibles, por duración 
en que coincidiera oferta ferroviaria y oferta de carretera. En la tabla que estamos comentado se ha indicado que estas líneas de autobuses ofrecían 580 paradas para dejar o recoger viajeros en localidades donde MZA tenía estaciones de ferrocarril, pero de una forma bastante desigual en sus efectos competitivos. Efectivamente, nueve líneas (2,4 por 100) realizan trayectos totalmente independientes de las estaciones de MZA. En 256 líneas (67,5 por 100) se produce la coincidencia con una estación ferroviaria, lo que hay que suponer beneficiaba más que perjudicaba al ferrocarril, al acercar por autobús el domicilio de clientes residentes en municipios algo alejados a la estación ferroviaria. Lo interesado de algunos de los lamentos de las Compañías quedaría patente por la no mención a esta complementariedad del autobús con el tren. A pesar de los anterior, es cierto que en las restantes líneas, en concreto en 114 (30 por 100), la coincidencia afecta a dos o más estaciones de MZA. En este último caso la competencia sí es palmaria $\mathrm{e}$, incluso, en aquellas líneas por carretera que sólo afectaban a una única estación, si bien aportaban viajeros de cortas y medias distancias al ferrocarril, es posible que en algún caso también pudieran detraerlos total o parcialmente mediante transbordos entre líneas por carretera, o entre éstas $\mathrm{y}$ recorridos ferroviarios.

Algunos datos concretos de los propios fecrrocarriles parecen demostrar esta competencia que tanto el transporte público por carretera como, sobre todo, el transporte en vehículos privados realizaban al ferrocarril especialmente en los trayectos cortos. $\mathrm{Y}$ es que estos trayectos de cercanías eran muy importantes también para el ferrocarril. Por ejemplo, en 1901, casi 2/3 partes de los viajeros que partían de la estación madrileña de Príncipe Pío tenían por destino estaciones de las provincias de Madrid, Segovia y Ávila, con semejante proporción en las estaciones de origen de los viajeros llegados a la misma estación de Norte, «lo que sugiere que se trataba de viajes de ida y vuelta» ${ }^{35}$. Si a ello añadimos, como se veía en los cuadros 1 y 2 y en el gráfico 1 , que el poco dinámico comportamiento de los ingresos por viajeros derivaba fundamentalmente de que «los viajeros/kilómetro experimentan un aumento pequeño hasta 1925 y desde ese año el descenso es prácticamente continuados ${ }^{36}$, y que, al menos en Norte, ese descenso afecta especialmente a las tarifas superiores, la de los usuarios

y frecuencia, del autobús frente al ferrocarril, los llamados «costos de usuario» por Thompson (1976), pp. 57 ss.

35 Gómez Mendoza (1989), pp. 168-169.

${ }^{36}$ Anes (1978), p. 477, refiriendose al subperíodo 1921-1935 y al conjunto de viajeros transportados por las redes de Norte, MZA y Andaluces. 
que por su nivel de ingresos se motorizarian antes, creo justificada la alarma de las compañías por el inicio de cierta competencia automovilística en el tráfico de viajeros bastante antes de la Guerra Civil.

\section{LAS RESPUESTAS DE LAS COMPAÑÍAS FERROVIARIAS ESPAÑOLAS}

Al menos las dos grandes compañías Norte y MZA intentaron reaccionar a estos inicios de la competencia automovilística en dos frentes, uno externo y otro interno, con diferente éxito. En el aspecto externo iniciaron una verdadera campaña, coordinada nacional e internacionalmente, para conseguir del poder político instauraciones o modificaciones de normas administrativas y fiscales que afectaban a los transportes por carretera. Con ello pretenderán que éstos se regulen de forma semejante al transporte ferroviario para evitar lo que denominan «competencia desleal». En el frente interno proyectaron e iniciaron una serie de actuaciones, en material fijo y móvil y también en aspectos organizativos, que intentaban adaptar al ferrocarril algunas de las ventajas comparativas del automóvil. Incluso, en última instancia, intentaron entrar en el mismo negocio del transporte por carretera.

$\mathrm{Ni}$ en uno ni en otro frente fueron originales - ni lo pretendieron-, puesto que tampoco era original de las compañías españolas el pasar por dificultades financieras y ver sus ingresos mordidos por la competencia de la carretera en el período de entreguerras. Valga como referencia contemporánea el que Marcel Peschaud, personaje vinculado a los ferrocarriles franceses, en un artículo de 1933, rápidamente traducido y publicado en España ${ }^{37}$, pasa revista al efecto de la competencia automovilítica sobre el ferrocarril en 22 países y a las reacciones producidas ${ }^{38}$. Con procedimientos de cálculo equivalentes a los que hemos mencionado de las compañías españolas, Peschaud cifra en un 10 por 100 las pérdidas que los ferrocarriles suizos y franceses tienen en sus ingresos habituales por esta competencia, el 13 por 100 en Alemania, 16 millones de libras en Gran

${ }^{37}$ Peschaud (1934). Es presentado en la publicación como «Secretario General del Comité de Dirección de las Grandes Redes Francesas» (sic).

38 Francia, Alemania, Austria, Bélgica, España, Gran Bretaña, Hungría, Irlanda, Italia, Letonia, Lituania, Noruega, Polonia, Portugal, Rumania, Suiza, Checoslovaquia, Yugoslavia en Europa; Argentina, Canadá y Estados Unidos en América, y Australia. De la generalidad internacional del asunto es una muestra también la obra de P. Wohl y A. Albitreccia, citada por Veenendaal (1996), Road and Rail in Forty Countries (1935). 
Bretaña y 800 millones de dólares sólo en el tráfico de pasajeros en los Estados Unidos. Muy interesado en las medidas legislativas internacionales reguladoras del transporte automovilístico ${ }^{39}$, muestra su admiración por las más intervencionistas y especialmente por aquellas que obligan a consultar a los ferrocarriles para la concesión de líneas de viajeros o mercancías por carretera, o que les otorgan derechos preferentes en su establecimiento ${ }^{40}$. Sobre las medidas tomadas por los distintos sistemas ferroviarios, el directivo francés destaca entre las más efectivas la entrada de las compañías en el negocio del transporte por carretera, ya muy desarrollado en Alemania, Gran Bretaña, Suiza y EEUU ${ }^{41}$; las actualizaciones tarifarias, de horarios y de servicios con el común denominador de la flexibilidad, incluyendo en ésta la posibilidad de cierre temporal o definitivo de líneas y estaciones; el empleo de container ${ }^{42}$; y las modificaciones en el material fijo y móvil que permitan reducción de costes y mayor eficiencia en el servicio (doble vía, electrificación, automotores, etc.). No debe sorprender la coincidencia temporal y conceptual de las medidas tomadas en los diversos países si tenemos en cuenta que las compañías ferroviarias han sido

39 Posiblemente por el retraso francés en la toma de medidas normativas equivalentes, a pesar de los proyectos de 1931 del Ministro Laval, rechazados por el Parlamento. Por ello, califica la acción del Estado francés de «harto endeble», p. 14.

${ }^{40}$ Destacan en este sentido, según Peschaud, el Decreto-ley de 6 de octubre de 1931 del Reich alemán [reproducido integramente también en MZA (1931), pp. 83.93]; la Ley húngara de 15 de octubre de 1931; la Ley belga de 21 de marzo de 1932; la Ley checa de 23 de diciembre de 1932; la Ley yugoslava de 9 de marzo de 1932, o las de los Estados australianos de Vitoria y Nueva Gales del Sur (1928 y 1931). Aun sin efectividad legislativa, comenta también extensamente el informe «Salter» británico de 1932 y el de la «Interestate Commerce Commission» norteamericana de 18 de abril del mismo año.

${ }^{41}$ En Alemania, como recientemente ha actualizado Mierzajewski (1996), el impulso dado por el régimen hitleriano hace que desde 1934 se superen los 60,9 millones de toneladas kilométricas transportadas en camiones propios o contratados por la Reichsbahn. También en Gran Bretaña desde las posibilidades abiertas por la legislación de 1928, según Peschaud, la inversión de los ferrocarriles en Compañías de automóviles les permitían controlar la explotación de 12.000 vehículos en 1933 (p. 37). Desde 1926 los CFF suizos crearon la Suisse-Express, S. A., que en 1931 contaba con 237 agencias y 365 servicios de camionaje que servían a 916 localidades (p. 52). Por último, la toma de control de compañías de carretra por las principales Compañías ferroviarias norteamericanas les permitieron tener 50.000 millas servidas por 4.000 autobuses y 7.000 camiones en 1930 . Un ejemplo de la actuación de dos de estas Compañías en Thompson (1998). Aunque no es citado por el autor francés, Veenendaal (1996) muestra lo mismo en los ferrocarriles holandeses con la creación de la ATO en 1927 y el progresivo control de nuevas empresas de transportes automovilísticos.

${ }^{42}$ Los ferrocarriles que más habían desarrollado este sistema eran los norteamericanos desde 1930, los alemanes (ya había 5.000 containers) y los británicos, donde en 1930 suponían el 0,58 por 100 del tráfico total de la región de Londres (p. 37). 
puestas como ejemplo de modernización empresarial ${ }^{43}$, lo que facilitaba la formación y funcionamiento regular de asociaciones internacionales y de sus estrategias de influencia. Así, en estos años se llevan a cabo diversas reuniones internacionales, en donde se incluyen muchas referencias a las relaciones entre el ferrocarril y la carretera, planteando una mayor regulación estatal del transporte por carretera, que fueron inmediatamente difundidas por los asociados, entre ellos los ferrocarriles españoles ${ }^{44}$.

Los intentos de las compañías para que en España se regulara con mayor detalle el transporte automovilístico debieron comenzar poco después de la primera regulación de 1924 que comenté en el epígrafe anterior. Tuvieron un relativo éxito en 1929 cuando se les da derecho de tanteo preferente en las solicitudes de la clase A (líneas regulares y exclusivas de viajeros) y se incluye a un representante de los ferrocarriles en la Junta Central de Transportes y en su comité permanente, encargado de otorgar estas concesiones y las de la clase $\mathrm{B}$ que coincidieran con otras líneas A existentes o fueran paralelas al ferrocarril ${ }^{45}$. Pero las funciones ejecutivas de esta Junta se suprimeron el 7 de octubre de 1930 traspasándolas a órganos unipersonales ${ }^{46}$ y en enero de 1932 se disolvieron estos organismos. Por otra parte, más por presión de los transportistas por carretera que por la de las Compañías ferroviarias, ya en 1930 se corta la concesión de nuevas licencias de clase A con «exclusividad», iniciando una revisión de las ya concedidas que continuará el Gobierno Provisional de la República por Decreto de 10 de mayo de 1931.

Los intentos de incrementar sustancialmente la fiscalidad de los transportes por carretera en relación al ferrocarril fueron prácticamente infructuosos. El esquema fiscal establecido en 1929 que fijaba como figuras impositivas la patente nacional de circulación, el canon de conservación de carreteras y el de inspección, el impuesto de transporte y el timbre no fue modificado antes de la Guerra Civil ${ }^{47}$ y suponía en 1931, según MZA,

${ }^{43}$ Chandler (1988), especialmente los capítulos 3 y 4. En el mismo sentido Vidal Olivares (1998), y para España, entre otros, Vidal Olivares (1996 y 1997).

${ }_{44}$ Por ejemplo, las Compañías españolas difundieron las conclusiones de la reunión de la Unión Internacional de Ferrocarriles celebrada en marzo de 1930 y de los Congresos Internacionales de Ferrocarriles de Madrid (1930) y El Cairo (1933). MZA (1931), pp. 71-77. Reparaz (1933).

${ }_{45}$ Real Decreto de 22 de febrero de 1929 (arts. 1. ${ }^{\circ}$ y $4 .^{\circ}$ ). El derecho de tanteo, sin embargo, se limita a «siempre que ofrezca ventajas en los servicios combinados entre ambos medios de transporte».

46 En concreto al Director General de Ferrocarriles, Tranvías y Transportes por Carretera, y las de las Juntas Provinciales a los Gobernadores Civiles.

${ }_{47} \mathrm{Si}$ se modificaron los tipos afectaron también a los ferrocarriles, de acuerdo con la Ley de Reformas Tributarias de 11 de marzo de 1932 [Imedio (1934), pp. 108-121]. 
poco mas de medio céntimo por viajero y kilómetro $(0,0056$ ptas.) para las concesiones por carretera de clase $\mathrm{A}$, mientras que el ferrocarril soportaba una fiscalidad tres veces mayor $(0,01689 \text { ptas. })^{48}$.

En definitiva, si bien los ferrocarriles españoles, en sintonía con los del resto del mundo, pretendieron por todos los medios a su alcance ${ }^{49}$ endurecer reglamentaria y fiscalmente la acción de los transportes por carretera a partir de la segunda mitad de los años veinte, el tamaño alcanzado por éstos, su consecuente capacidad de presión y la debilidad política de unas compañías en vías de nacionalización limitaron la eficacia de sus actuaciones hasta el extremo de que en España los ferrocarriles seguían consedirándose muy perjudicados, llegando a abogar en 1936 por una limitación pura y dura de la importación de automóviles ${ }^{50}$.

En las medidas que podemos considerar pertenecientes al frente interno, también consiguieron éxitos muy desiguales, con el inconveniente que el estallido de la Guerra Civil y sus duraderas consecuencias yuguló en sus inicios algunas de las iniciativas más prometedoras. En los decretos de 1929, los ferrocarriles consiguieron la inclusión de la figura de «Despachos Centrales» que se refiere a los servicios combinados ferrocarrilautobús (correspondencia o factaje) y ferrocarril-camión (camionaje o reexpedición) entre estaciones de ferrocarril y poblaciones cercanas ${ }^{51}$, establecidos mediante contrato por las Compañías ferroviarias y transportistas por carretera y autorizados por la Administración. De alguna forma, el incremento de la vinculación con el ferrocarril, de algunas de aquellas 256 líneas mencionadas en la tabla 5, que sólo tocaban una estación de MZA en su recorrido, y que suponíamos eran complementarias del ferrocarril más que competidoras. Por ello, estos Despachos Centrales van a ser en España el mecanismo más empleado para el aprovechamiento por parte de los ferrocarriles de la coordinación con el automóvil, bien para alargar sus servicios ferroviarios a poblaciones en donde la distancia dificultaba el acceso a sus muelles, bien para ofrecer servicios en las grandes ciudades fuera de las estaciones.

${ }^{48}$ MZA (1931), p. 30.

49 Para algunas de las más importantes publicaciones de los ferrocarriles ver la referencia bibliográfica. Vieron la luz como documentos de trabajo o conclusiones de las «Conferencias» organizadas por el Gobierno en 1932 y 1934.

${ }^{50}$ Norte (1940) y Asociación General de Transportes por vía férrea (1936), p. 11.

"1 Limitados inicialmente a $5 \mathrm{~km}$, pero ampliados a 20 en diciembre de 1929 , y desde la Orden de 27 de junio de 1931, «sin limitación de distancias cuando los trayectos que los servicios hayan de recorrer no afecten a líneas de transportes mecánicos por carretera». 
Aunque la primera relación localizada de estos Despachos corresponde a $1940^{52}$, podemos suponer que su estrucura representa un mínimo a la existente antes de la Guerra Civil. Pues bien, ese mínimo es una red de 156 líneas con un recorrido total de $3.005 \mathrm{~km}$ y servida por 503 vehículos. Incluye 333 localidades españolas de 38 provincias ${ }^{53}$ y 123 estaciones de ferrocarril. La mitad de los 156 Despachos afectan exclusivamente a la localidad donde radica la estación, el 31 por 100 ponen en relación un núcleo de población sin ferrocarril con una estación y el resto, 19 por 100 , tienen itinerarios que pasan por tres o más localidades. Entre los concesionarios de estos servicios sólo aparecerán las propias Compañías ferroviarias en el caso de los cinco Despachos madrileños ${ }^{54}$, y en los Despachos cántabros de Santoña y Laredo, cuya concesión corresponde al Ferrocarril de Santander a Bilbao. El resto son concesionarios sin aparente vinculación con el ferrocarril. Este hecho nos muestra un fuerte atraso frente a otros países en la entrada directa de los ferrocarriles españoles en el negocio del transporte por carretera. Mientras habíamos comentado 55 las inversiones de los ferrocarriles americanos, británicos, alemanes, holandeses o suizos, creando o controlando empresas de transporte por carretera desde mediados de los años veinte, la única iniciativa que conocemos de las grandes Compañías españolas, aunque solamente de nombre, es la constitución a fines de 1934 de la sociedad Ferrocarriles y Autobuses Combinados (FAC), formada por Norte, MZA y la empresa de transporte por carretera Sociedad Alsina Graells ${ }^{56}$.

Al igual que sus colegas extranjeros, los ferrocarriles españoles iniciaron modificaciones en sus infraestructuras y servicios buscando tanto una disminución de costos como una mayor flexibilidad para competir en mejores condiciones con la carretera. Algunas veces, ello implicaba modificaciones

52 Imedio (1940), pp. 205-209 y 253-258.

53 Si bien, muy desigualmente repartidos. Cataluña es la región española que, con mucho, cuenta con la mayor red de Despachos Centrales, pues allí se concentran 51, especialmente en las provincias de Barcelona (27) y Gerona (15). Tras ellas, con un número significativo, sólo Jaén (nueve), Alicante (siete), Albacete y Madrid (seis) y Cáceres, Córdoba y Valencia, con cinco Despachos cada una.

54 En donde en todo ellos hay vehículos de MZA, en tres de Oeste y en uno de Norte.

55 Ver nota 38.

56 Norte (1940), p. 304. Su objeto era la explotación de las concesiones de líneas de autobuses paralelas a las vías férreas, cuyas posibilidades aumentó ligeramente el Decreto de 19 de julio de 1934. Algunos directivos ferroviarios españoles, como Juan A. Bravo, eran muy reticentes aún en 1932 a la creación de compañías por los propios ferrocarriles, prefiriendo los contratos de prestación de servicios y asociación «con los elementos indígenas en cada población o comarca» [Bravo (1934), p. 36]. 
en los organigramas de las compañías para el estrechamiento de líneas de colaboración interempresarial. Así, se potenciaron comités de enlace preexistentes, como los creados por Norte y MZA en 1923 de «Servicios Comunes de Estudios, Coordinación con la Carretera y Cambios de Material», el «Parque Mancomunado de Material», o la posterior «Oficina Común Liquidadora y Reguladora del Tráfico Combinado», o el más definitivo contrato de sindicatura de tráficos entre ambas Compañías y el Central de Aragón de $1935^{57}$.

Habíamos indicado cómo internacionalmente se había intentado mejorar la prestación de servicios ferroviarios mediante la introducción de renovaciones en la infraestructura ferroviaria que permitieran una mayor fluidez y velocidad de circulación para competir mejor contra el automóvil y aumentar la productividad ferroviaria. Entre las posibilidades de acción, tecnológicamente viables en la época, hay que destacar los desdoblamientos de la vía, la electrificación, la mejora en la señalización, la introducción de automotores y el empleo de containers. Aunque, salvo en el último, en todos ellos hubo avances ${ }^{58}$, se debe adelantar que posiblemente por la certeza de las compañías en lo ineludible de la nacionalización y por el crecimiento de los gastos de explotación no fue suficiente el esfuerzo inversor $^{59}$, por lo que los logros alcanzados antes de la Guerra Civil fueron bastante modestos. De los 12.791 kilómeros de líneas ferroviarias integradas en RENFE en 1941, sólo había 1.797 de doble vía (14 por 100), mientras que esa proporción era en 1938, respectivamente, del 63, 50, 40 y 27 por 100 en los ferrocarriles británicos, franceses, alemanes e italianos ${ }^{60}$. En 1935 había en España 960 km. electrificados y de éstos tan sólo 427 km correspodían a ferrocarriles de vía ancha, casi en exlusiva de la Compañía del Norte ${ }^{61}$. Con estas limitaciones no es de extrañar que el parque eléctrico de vía ancha en enero de 1935 se limitara a 74 locomotoras y ocho

57 Norte (1940), p. 303 (Orden Ministerial de 9 de marzo de 1935).

${ }^{58}$ El empleo de containers se nombra en varias publicaciones, pero no hay constancia alguna de su uso en España hasta muchos años después. En señalización, aunque tardíamente, se introdujo en la década de los veinte el sistema automático o block-system. Cordero y Menéndez (1978), p. 315.

${ }^{59}$ Artola (1978), p. 423.

${ }^{60}$ Muñoz (1995), pp. 112-114. Las dobles vías españolas casi se limitaban a la línea de Norte del Madrid a Irún y a la de MZA de Madrid-Albacete, y a algunos tramos cortos en Bilbao, Palencia, Zaragoza, Barcelona y Sevilla.

${ }^{61}$ Se trata de los tramos de Pajares $(62 \mathrm{~km})$ realizados en 1925, Barcelona-San Juan de las Abadesas $(170 \mathrm{~km}$ ) en servicio desde 1928, y un año después los de Irún-Alsasua $(105,5 \mathrm{~km})$ y Ripoll-Puigcerdá $(49 \mathrm{~km})$. El resto son los $30 \mathrm{~km}$ de Gádor a nacimiento 
automotores, a lo que habría que añadir 25 locomotoras y 46 automotores eléctricos de vía estrecha ${ }^{62}$.

Por último, las Compañías españolas también prestaron atención a las posibilidades de los automotores térmicos para competir con el autobús en zonas de alta densidad urbana ${ }^{63}$. En 1931, MZA reconoce estar en contacto con varías empresas constructoras europeas ${ }^{64}$, Norte realiza ensayos con vehículos equipados con motores Ford de gasolina o Beardmore y Ganz (Diesel) en 1935 y tenía encargadas 50 unidades en el momento del estallido de la Guerra Civil ${ }^{65}$. Incluso en la línea de colaboración interempresarial antes comentada llegó a constituirse en 1936 la Compañía Nacional de Automotores, formada por Norte, MZA y cinco Bancos, como intermediaria financiera para la adquisición de automotores ${ }^{66}$.

\section{CONCLUSIÓN}

Es perfectamente conocido que las Compañías ferroviarias españolas vivieron durante los años veinte y la primera mitad de los treinta una complicada situación económica y en sus relaciones con el Estado que puede resumirse en la expresión Problema Ferroviario. He intentado demostrar cómo el fuerte crecimiento de la motorización española contemporáneo al «Problema», al iniciar la competencia del tranporte automóvil con los demás modos terrestres, por una parte afectó claramente al transporte tradicional movido con caballerías, de lo que se han aportado algunos indicios, pero además añadió un factor exógeno a la crisis ferroviaria que parece afectó sensiblemente a su capítulo de ingresos.

Las propias Compañías, como en otros países, le adjudicaron un papel esencial, además de duradero y creciente en la explicación de los descensos del tráfico. Para las dos grandes españolas, Norte y MZA, aunque quizá de forma exagerada, el papel de la carretera era más preocupante que los efectos de la crisis de 1929, por suponerse con acierto que el tiempo no haría más que incrementar su competencia. Ello era así posiblemente

de la Compañía Oeste-Andaluces (la primera electrificación española llevada a cabo en 1911) y 9 km del Bilbao-Portugalete (1929). Norte (1940), p. 407, y RENFE (1995), pp. 14-15. ${ }^{62}$ De la Torre (1935), pp. 164-167.

${ }^{63}$ A 1 de enero de 1935 hay en funcionamiento en el conjunto del sistema ferroviario español 39 automotores, al menos, no especificados como eléctricos. Ibidem.

${ }_{64}$ MZA (1931), p. 48.

${ }^{65}$ Norte (1940), p. 305, y RENFE (1995), pp. 108-114.

${ }^{66}$ Norte (1940), p. 306. 
porque ese fuerte incremento de la infraestructura de transporte por carretera desde 1923 permitía que hacia 1930 el automovilismo español tuviera una capacidad operativa similar — algo menor en capacidad de carga de mercancías pero superior incluso en los vehículos de turismo-a la existente a mediados de los años cincuenta, por la prolongada crisis postbélica y del período franquista más autárquico. Y en 1950 ya se está en condiciones de observar, con las estadísticas oficiales españolas, que la carretera estaba a punto de superar definitivamente al ferrocarril. Así, esa capacidad de transporte por carretera no pudo menos que atacar, aunque fuera parcialmente, a los ingresos regulares del transporte ferroviario español, aquejado además desde fines de la Primera Guerra Mundial de serios problemas financieros por el lado de los gastos.

De esta forma en los primeros años treinta la capacidad de carga en viajeros y mercancías del parque automovilístico español se traduce para los ferrocarriles en una competencia que se traduce en una pérdida de ingresos, principalmente en los originados por el tráfico de viajeros - de $2 .^{a}$ y $1 .^{\text {a }}$ clase - y el transporte de las mercancías con tarifas más remuneradoras, las de la Alta Velocidad, como muestran los resúmenes contables de las principales Compañías, en contraste con las marcha más brillante del tráfico de mercancías voluminosas de la Pequeña Velocidad. Pero no se debe olvidar que en consonancia con lo que sucede en la motorización de otros países europeos, en esos momentos la competencia en esos segmentos de mercado de transporte se reduce además a los trayectos inferiores a 100 kilómetros.

El nuevo escenario dibujado con la aparición del automóvil hace que, al igual que sus colegas internacionales, las compañías españolas intentaran diversos remedios, externos e internos, para mitigar esta imparable competencia, aunque sus específicos «problemas» limitaran fuertemente la intensidad inversora que se requería y con ello las respuestas efectivas, que, además, quedarían dramáticamente paralizadas con el estallido de la guerra en 1936. La Guerra Civil y la autarquía franquista, aunque también perjudicó a los ahora nacionalizados ferrocarriles españoles ${ }^{67}$, al afectar aún más duramente a los inputs automovilísticos, atrasó hasta los años cincuenta el momento en que el transporte por carretera superará definitivamente el número de viajeros y toneladas de mercancías transportadas sobre carriles de hierro, lo que había estado a punto de poder conseguir antes del conflicto bélico.

${ }^{67}$ Muñoz (1995), pp. 137-169. 


\section{BIBLIOGRAFÍA}

ANES, R. (1978): «Relaciones entre el ferrocarril y la economía española (1865-1935)», en ARTOLA, M. (dir.), Los ferrocarriles en España. 1844-1943, vol. II, Madrid, Banco de España, pp. 355-512.

Artola, M. (1978): «La acción del Estado», en ARTOLA, M. (dir.), Los ferrocarriles en España. 1844-1943, vol. I, Madrid, Banco de España, pp. 341-454.

Asociación GENERAL de TRANSPORTES POR VÍA FÉRREA (1936): La influencia del automóvil en el desnivel de la balanza de pagos, Madrid.

AuTRÁN, E. de (1932): El problema ferroviario en España. Sus orígenes, causas que lo agravaron y medio radical de resolverlo. Conferencia leida en el Ateneo Científico, Lieterario y Artístico, de Madrid, en la tarde del día 26 de febrero de 1932 (Biblioteca Nacional. VC-1068-8).

BARKER, T. (1987): «A German Centenary in 1986, a French in 1995 or the Real Beginnings about 1905?», en BARKER, T. (ed.), The Economic and Social Effects of the Spread of Motor Vebicles. An International Centenary Tribute, Hong Kong, MacMillan Press, pp. 1-54.

BARKer, T., y Gerhold, D. (1993): The Rise and Rise of Road Transport, 1700-1990, London, MacMillan Press.

Bravo, J. A. (1932): Modificaciones a introducir en la explotación de los ferrocarriles en relación con el transporte mecánico por carretera. Aportación a los trabajos de la Conferencia Nacional de Transportes, Madrid, Asociación General de Transportes por Vía Férrea.

CARRERAS, A. (1988): «España durante la 2.a revolución tecnológica», en MinISTERIO DE INDUSTRIA y ENERGÍ, España: 200 años de tecnología, Madrid, pp. 101-195.

- (1990): Industrialización española: estudios de bistoria cuantitativa, Madrid, Espasa-Calpe.

CAtAlÁN, J. (1995): La economía española durante la Segunda Guerra Mundial, Barcelona, Ariel.

CECA (1975): Estadísticas Básicas de España. 1900-1970, Madrid, CECA.

Comin, F.; Martín Aceña, P.; Muñoz Rubio, A., y Vidal Oldvares, J. (1998): 150 Años de Historia de los Ferrocarriles Españoles, Madrid, Fundación de los Ferrocarriles Españoles, 2 vols.

Compañías de los FerRoCarriles del NorTe de España y MZA (1934): Informe sobre el proyecto de Ley de Ordenación Ferroviaria leido en las Cortes el 21/6/1934, Madrid, Gráfica Administrativa.

Compañía de los Caminos de Hierro del Norte de España (Norte) (1940): 1858-1939. Historia, actuación, concesiones, ingresos, gastos y balance, Madrid, Espasa-Calpe, S. A.

Compañía de los Ferrocarriles de Madrid a Zaragoza y Alicante (MZA) (1931): La coordinación del transporte mecánico por carretera con el ferrocarril. Comen. tarios al proyecto de Ley sobre el Servicio Público de transportes por carretera presentado a las Cortes Constituyentes por el Ministro de Fomento en 6 de octubre de 1931, Madrid, Gráfica Administrativa.

Cordero, R., y MENÉNDEZ, F. (1978): «El sistema ferroviario español», en ArTOLA, M. (dir.), Los ferrocarriles en España. 1844-1943, vol. I, Madrid, Banco de España, pp. 163-340. 
ChANDLER, A. D. (1988): La mano visible: la revolución en la dirección de la empresa norteamericana, Madrid, Ministerio de Trabajo y Seguridad Social.

Gómez MENDOzA, A. (1989a): Ferrocarril, industria y mercado en la modernización de España, Madrid, Espasa-Calpe.

- (1989b): «Transportes y comunicaciones», en CARRERAs, A. (coord.), Estadísticas Históricas de España. Siglos XIX-XX, Madrid, Fundación Banco Exterior, pp. 269-326.

GEHR (1983): «Notas sobre la producción agraria española, 1891-1931», Revista de Historia Económica, I, núm. 2, pp. 185-252.

HeRnández MarCo, J. L. (1996), "La oferta automovilística en España antes del "Seat-600": 1906-1957», Economía Industrial, núm. 307, pp. 131-148.

- (1997): Trenes, Estaciones y Puertos: El Tráfico de Mercancías de la Cía. del Norte (1876-1930), Bilbao, Gobierno Vasco, Departamento de Transportes y Obras Públicas.

JimÉnez Blanco, J. I. (1986): «Introducción», en GarRabou, R.; BarCiela, C., y Jiménez Blanco, J. I. (eds.), Historia Agraria de la España Contemporánea. 3. El fin de la agricultura tradicional (1900-1960), Barcelona, Crítica, pp. 9-141.

JimÉnez Ontrveros, F. (1932): Problemas de la economía nacional. El automóvil $y$ el ferrocarril. La competencia que ofrecen al ferrocarril los transportes mecánicos por carretera. La construcción de nuevos ferrocarriles, Madrid, Blass, S. A.

LOPEz GómEz, A. (1983): Los transportes urbanos de Madrid, Madrid, CSIC, Instituto «Juan Sebastián Elcano».

Imedio DíAz, J. (1934): Transportes por carretera. Con un apéndice cronológico de disposiciones acotadas y concordadas, Madrid, Imp. Sáez Hermanos.

- (1940): Anuario de los Ferrocarriles y de sus Transportes Coordinados, Madrid, Gráfica Administrativa.

INE (1952): Estadística de Vebículos Automóviles Matriculados de Propiedad Particular, Madrid, INE.

IZQUIERDO DE BARTOLOMÉ, R. (1981): «El modelo de transporte», en ACOSTA ESPAÑA y otros, La España de las Autonomías (pasado, presente y futuro), tomo Y, Madrid, Espasa-Calpe, pp. 367-479.

Mierzejewski, A. C. (1996): «The German National Railway Confronts its Competitors, 1920-1939», Bussines and Economic History, 2. ${ }^{2}$ ed., vol. 25, núm. 2, pp. 89-102.

Martín ACeña, P., y Comín, F. (1991): INI. 50 años de industrialización, Madrid, Espasa-Calpe.

Muñoz Rubio, A. (1995): Renfe (1941-1991): medio siglo de ferrocarril público, Madrid, Luna.

Peschaud, M. (1934): El problema del ferrocarril y de la carretera en Francia y en los principales países extranjeros, Madrid, Asociación General de Transportes por Vía Férrea.

RENFE (1995): Del vapor al Ave, Madrid, Fundación de los Ferrocarriles Espanoles.

Reparaz, F. (1933): El Congreso de Ferrocarriles de El Cairo, Madrid, Asociación General de Transportes por Vía Férrea.

- (1936): Consideración económico-política de la coordinación de los transportes terrestres, Madrid, Revista de Obras Públicas. 
SAN ROMÁN, E. (1995): La industria del automóvil en España: el nacimiento de Seat, Madrid, Fundación Empresa Pública, Documento de trabajo 9503.

Tedde, P. (1978): «Las Compañías ferroviarias en España (1855-1935), en ArTola, M. (dir.), Los ferrocarriles en España. 1844-1943, vol. II, Madrid, Banco de España, pp. 9-354.

Tortelia, G. (1994): El desarrollo económico de la España contemporánea, Madrid, Alianza Editorial.

Thompson, G. L. (1996): «The Passenger Train in the Motor Age: The California Experience, 1910-1941», Bussines and Economic History, 2." ed., vol. 27, pp. 219-226.

Thompson, J. M. (1976): Teoría económica del transporte, Madrid, Alianza Editorial.

TORRE, E. de la (1934 y 1935): Anuario de Ferrocarriles y Tranvías, Años XXXIX y XI.

VEENENDAAL, A. J. (1996): «Railways and the coming of motor transport in the Netherlands, 1919-1940», Bussines and Economic History, 2. ${ }^{a}$ ed., vol. 25, núm. 1, pp. 293-300.

VIDAL OlIVARES, J. (1996): «Las compañías ferroviarias y la difusión de las modernas formas de gestión empresarial en España, 1850-1914», en CoMín, F., y MARTíN ACEÑa, P. (eds.), La Empresa en la Historia de España, Madrid, Civitas, pp. 285-302.

- (1998): «Introduction», en Armstrong, J.; Bouneau, C., y Vidal Olivares, J., Railway management and its organisational structure: its impact and diffusion into the general economy, Sevilla, $12^{\text {th }}$ International Economic History Congress, sesión B-14.

VILLALONGA, I. (1932): Notas sobre la reglamentación jurídica del servicio del transporte mecáncio por carretera. Aportación de los trabajos de la Conferencia Nacional de Transportes, Madrid, Gráfica Administrativa.

VIves, B. (1932): El problema de la coordinación de los transportes ferroviarios y de los mecánicos por carretera. Aportación a los trabajos de la Conferencia Nacional de Transportes, Madrid, Asociación General de Transportes por Vía Férrea. 